\title{
NEFROPATÍA Y DISMORFISMO GLOBULAR EN SEDIMENTO URINARIO
}

Diana Maritza Amaya* Erika Fernanda Vargas Pinilla * Deissy Vargas Montañez *

\section{Resumen}

Este trabajo de investigación tiene como objetivos describir la importancia de la cuantificación del dismorfismo globular en el sedimento urinario de pacientes con estudio histológico de biopsia renal, como ayuda diagnóstica de nefropatías, al igual que determinar la frecuencia de estas alteraciones y comparar los hallazgos del sedimento urinario con la biopsia. Las muestras fueron obtenidas de diez enfermos mayores de 18 años que acudieron a la unidad renal del Hospital de San José, y a quienes se les realizó cuantificación de dismorfismo antes de la biopsia. De los diez pacientes analizados, dos presentaron dismorfismo globular menor del $50 \%$, seis entre 51 y $80 \%$ y en dos fue mayor del $81 \%$.

Se observó que puede existir relación entre dismorfismo globular en sedimento urinario y nefropatías, sin embargo, se requieren estudios y pruebas diagnósticas mejor estructurados, con el fin de ampliar los conocimientos adquiridos sobre este tema.

Palabras clave: dismorfismo globular en sedimento urinario, hematuria, eumórficos.

\section{Introducción}

El análisis del sedimento urinario constituye el punto de partida para el estudio de pacientes con enfermedad renal y es una prueba para confirmar la presencia de procesos patológicos a ese nivel. La eficacia de la toma del sedimento urinario es un método postulado como una necesidad diagnóstica pues la hematuria microscópica permite establecer cambios morfológicos dentro de un amplio espectro de posibilidades nosológicas a la hora de su lectura. Debido a la falta de estudios que brinden confiabilidad y veracidad, se pretende realizar la búsqueda de un procedimiento eficiente y un diagnóstico primario racional de nefropatías, implementando así el uso rutinario de esta técnica.

Al observar que la morfología de los eritrocitos es normal, puede sospecharse que la hematuria se origina en las vías urinarias, a diferencia de cuando existe presencia de eritrocitos deformes, distorsionados, fragmentados o "dismórficos", que son un indicio claro de que el origen es glomerular, el cual

\footnotetext{
Estudiantes de IV y VI Semestres Facultad de Citohistotecnología, Fundación Universitaria de Ciencias de la Salud, Hospital de San José.

Este trabajo fue realizado en la Unidad Renal del Hospital de San José de Bogotá, durante 2004, bajo la tutoría del Dr. Carlos Roselli Sanmartín, Jefe del Servicio de Nefrología, Hospital de San José, Instructor Asociado, Fundación Universitaria de Ciencias de la Salud.
}

se sospecha cuando más del $20 \%$ de los glóbulos tienen este aspecto dismórfico. La presencia de más del $80 \%$ de eritrocitos normales o "eumórficos", sugiere un origen postglomerular o subrrenal. De todas maneras, la observación de los hematíes normales, sobre todo cuando aumenta el flujo urinario, no descarta una enfermedad del glomérulo.

\section{Materiales y métodos}

El tipo de diseño del trabajo de investigación es descriptivo y se ajusta a un reporte de casos. Para el cumplimiento del estudio planteado, se realizó la técnica de dismorfismo globular en sedimento urinario establecida en el laboratorio clínico del Hospital de San José. Se incluyeron diez pacientes con nefropatías que fueran mayores de edad. Se excluyeron aquellos cateterizados, con carcinoma de vías urinarias o de próstata, enfermedad litiásica, trauma o infección de vías urinarias y mujeres con menstruación.

\section{Resultados}

De los diez pacientes analizados el $80 \%$ eran de sexo masculino y el $20 \%$ femenino. Dos presentaron dismorfismo globular menor del $50 \%$, uno de sexo masculino de 38 años con lesión esclerosante 
glomerular (no inmune) y otro femenino de 43 años con lesión membranosa de grado II/IV y membrana delgada. Seis cursaron con dismorfismo globular entre el 51 y el $80 \%$, de los cuales cinco eran de sexo masculino con edades de 21,30,47,48 y 71 años, cuyas lesiones fueron: esclerosante focal, membrano-proliferativa lúpica, nefropatía IgA, membranosa II- III/IV, nefropatía IgA II-III/IV, y uno de sexo femenino de 57 años con lesión esclerosante focal con depósitos de IgM. Dos pacientes de sexo masculino presentaron un dismorfismo mayor del $81 \%$ (55 y 28 años) y el resultado de la biopsia renal fue nefropatía IgA III / IV, y nefroarterioesclerosis de tipo diabético.

\section{Discusión}

El examen del sedimento urinario puede indicar evidencia de enfermedad renal. Así mismo proporciona información sobre los riñones y vías urinarias que se correlaciona con el estado clínico del paciente. Debido a la falta de estudios sobre el análisis del dismorfismo globular, algunos autores mencionan que el mecanismo del daño en los eritrocitos para crearlo es desconocido, pero ha sido atribuido al rompimiento físico durante el paso directo por la membrana basal glomerular y al trauma osmótico cuando pasa por el nefrón distal.

Estudios previos han reportado la presencia de eritrocitos dismórficos en pacientes con enfermedad renal versus lesión del tracto urinario bajo y muestran sensibilidad colectiva del $95 \%$ y especificidad del $92 \%$. La hematuria glomerular se sospecha cuando más del 20\% de los eritrocitos tienen aspecto dismórfico; la observación mayor del $80 \%$ de eritrocitos normales sugiere un origen postglomerular o subrrenal. De todas maneras, la presencia de hematíes normales, sobre todo cuando aumenta el flujo urinario, no descarta una enfermedad del glomérulo.

\section{Recomendaciones}

Se pretende crear la inquietud acerca del tema, para que este sea abordado con estudios más avanzados que ayuden a confirmar la eficacia de la técnica para diagnóstico de procesos patológicos renales, que faciliten tanto al paciente como al personal médico concluir un diagnóstico confiable. Se busca aplicar como método de rutina cuando consultan por cuadro clínico sospechoso de nefropatía.

El manejo adecuado de esta técnica y la correcta aplicación de la misma a la hora de manipular la muestra, son aspectos importantes que pueden servir de ayuda para obtener un resultado más preciso. Al final del estudio se plantean las siguientes hipótesis con el fin de crear inquietud acerca del tema: ¿Qué tan efectiva puede resultar la utilización de la técnica de dismorfismo globular en sedimento urinario para aplicaciones clínicas? ¿Qué factores se deben tener en cuenta para aplicar la técnica como ayuda diagnostica en nefropatías? ¿Qué aspectos son importantes a la hora de realizar estudios más avanzados acerca del tema?

\section{Lecturas recomendadas}

Birch D F, Fairley K F, Whitworth J A, et al Urinary erythrocyte morphology in the diagnosis of glomerular hematuria. Clinic Nephrology, 1983; 20: 78-84.

Chang Bs. Red cell morphologyas a diagnostic aid in hematuria. JAMA 1984; 252: 1747-49.

Fairley KF, Birch DF. Hematuria simple method for identifying glomerular bleeding. Kidney Int 1982; 21: 105-8.

Rosemberg H. Anatomía patológica del aparato urinario genital masculino. (Citado 2004 noviembre 21) disponible en www.escuela.med.puc.cl.

Stephan R, Eckhad R. Rathert P.Microscopic hematuria: advances in identification of glomerular dysmorphic erytrocytes. J. Urology 1991; 146: 680-84.

Torres A, Sellares V. Manual de Nefrología. Madrid: Manual Moderno Harcourtk, 1998, p.3.

Villanueva V. Enfoque diagnóstico de hematuria. (Citado 2001 feb) Disponible en www.escuela.med.puc.cl.

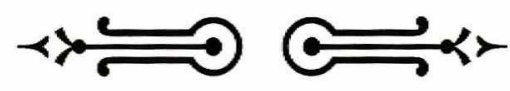

